\title{
Maria Bernardete
}

Castelán Póvoas: uma

história de docência e

arte

Rafael Dias de Oliveira 
Este artigo traz a narrativa de Maria Bernardete, professora do CEART desde sua fundação e que participou ativamente do processo de implantação do centro, exercendo vários cargos administrativos. Atua no ensino, pesquisa e extensão. A partir de sua narrativa, é possível conhecer um pouco da história do CEART, da data de sua fundação até os dias atuais. Utilizando a pesquisa narrativa enquanto método, esse trabalho considera a narrativa em questão como história oral, que consiste na reunião de reflexões pessoais sobre eventos.

Palavras-chave: História Oral; CEART; Música; Profissão Docente.

\section{Introdução}

A escolha do nome de Maria Bernardete Castelan Póvoas para Centro de Artes (CEART) a partir de depoimentos de professores não foi por acaso. Natural de Criciúma (SC), é professora de música no ensino superior da rede estadual de Santa Catarina desde 1975, participou e presidiu comissóes decisivas no caminho que a arte percorreu desde a década de 70 com o curso de Licenciatura Curta em Educação Artística vinculado à Faculdade Estadual de Educação (FAED) até o CEART atual. Como ela mesma se define, hoje é uma "musicista professora" e "está pianista". Segundo ela, um dos principais motivos porque não "esteve pianista" em alguns momentos de sua vida foi por estar se dedicando a atividades administrativas no curso de Educação Artística e, posteriormente, no CEART.

A professora Bernardete atua até hoje na pesquisa orientando trabalhos de mestrado no programa de Pós-Graduação em Música (PPGMUS) da Universidade do Estado de Santa Catarina (UDESC) na linha de práticas interpretativas e mantém desde 1999 o grupo de pesquisa Processos Músico-Instrumentais, envolvendo professores, estudantes de pós-graduação e graduação dessa mesma universidade.

Apaixonada pela arte defende que professores de um centro de artes não podem pensar somente na produção acadêmica, mas também em uma produção artística e dar foco a essa produção. Nesse sentido, como pianista, Bernardete possui trabalhos como solista e camerista. Sua produção artística envolve projetos como o Piano Duo 
(1987-2000), aonde com a pianista Denise Cordeiro realizou recitais em vários estados brasileiros e recebeu um prêmio de um concurso internacional para duos pianísticos. Em 2010 recebeu o prêmio Franklin Cascaes - destaque música Erudita. Desenvolveu intenso trabalho ao lado da soprano Rute Gebler, do pianista Luís Cláudio Barros e em 2011 realizou a turnê Piano Brasileiro com a pianista Mauren Frey em Portugal e na França.

Foi exatamente sobre esse assunto, a arte, que começamos a nos preparar para a entrevista que ocorreu em uma sexta feira de tarde, já em clima de fim de semana. Antes de começar oficialmente e ligar o gravador, ela contou como tinha sido o recital em que havia tocado na noite anterior, como a música tinha sido "intensa" e como a arte mexe com as pessoas. Durante uma hora de entrevista, a professora Bernardete contou um pouco da sua história como docente. Creswell (2014, p. 70) chama este tipo de narrativa de história oral, que consiste na reunião de reflexóes pessoais sobre eventos. O autor (idem, p. 68) explica que a pesquisa narrativa enquanto método começa com as experiências expressas nas histórias vividas pelos indivíduos e que narrativa pode ser um texto falado ou escrito que conecta cronologicamente uma série de eventos ou açôes.

A partir da história falada da professora Bernardete é possível compreender um pouco mais sobre a constituição e evolução do Centro de Artes da UDESC, sob a visão de uma pessoa que vive as salas de aula, os auditórios e os espaços administrativos do CEART, desde sua criação há 30 anos.

\section{Sua história como professora conta a história da arte na UDESC}

R ernardete começou sua carreira como professora no ensino Buperior da rede estadual de Santa Catarina na Faculdade Estadual de Educação (FAED) lecionando harmonia para o curso de Licenciatura Curta em Educação Artística. Porém, sua entrada como funcionária do Estado de Santa Catarina ocorreu alguns anos antes.

Quando terminou o segundo grau, atual ensino médio, fez um concurso para o magistério na rede estadual de ensino e foi admitida como professora em uma escola na cidade de Criciúma. Logo em seguida, prestou vestibular e passou para o curso de 
Bacharelado em Piano da Universidade Federal do Rio Grande do Sul (UFRGS). Segundo a professora, naquela época era permitido ao professor da rede estadual fazer um curso superior que náo existia em Santa Catarina em outro estado, mantendo o vínculo profissional como professor licenciado, podendo fazer o curso e se manter como servidor estadual. Ela conta que esteve nessa condição por duas vezes: durante a graduação em Porto Alegre e durante o período de cinco anos que passou na França estudando piano em um conservatório.

Ao retornar da França, precisava assumir seu cargo no estado, mas naquele momento não havia vaga para professor e foi, então, locada para trabalhar em serviços burocráticos em uma secretaria de estado. Desse período não mostra saudades quando diz de forma enfática: "eu caí ali, digamos aterrissei ali, parecia cargo político. Colocaramme ali e eu não sabia o que fazer, foi uma tortura, porque me dava um sono danado, eu não tinha o que fazer." Insatisfeita, conseguiu sua transferência para trabalhar na FAED em serviços administrativos.

Logo começou a ajudar no coral que ali existia e a se estabelecer no local. Depois de um semestre, surgiu a necessidade de um professor de Harmonia e ela assumiu essas aulas, no início, ainda, como professora do magistério à disposição e, depois, foi contratada oficialmente como professora do curso de Educação Artística Licenciatura Curta que, como ela explica "era um curso de dois anos e tinha um pouquinho de música, um pouquinho de cada área. Nós éramos, digamos, um braço da faculdade de educação, o curso fazia parte dela”.

\section{"A história da implantação do CEART daria uma novela"}

De 1979 a 1985, a professora Bernardete participou ativamente dos grupos de discussóes e comissões que foram fundamentais na consolidação da arte na UDESC. Nesse período, ocorreu a criação do curso de Licenciatura Plena em Educação Artística com Habilitações em Música, Artes Plásticas e Desenho, com mais quatro semestres e a transição do curso para o Centro de Artes. Em 1980 e 1982 presidiu a Comissão de Estudo para Reestruturação do Curso de Educação Artística e em 1979 participou da Comissão de Estudos que já se formava para a Implantação do Centro de Artes.

Dessa época traz uma recordação curiosa. Segundo a professora, 
existia e, ainda, existe uma "concepção errada de que os cursos de artes são os mais caros da UDESC, por ter aulas individuais, por exemplo". Ela fala sobre um movimento na reitoria, "sobretudo um senhor" que achava que as licenciaturas em artes eram muito caras e não eram necessárias. Foi, entâo, lançado um edital para o vestibular sem o curso de Educação Artística e ela como diretora do curso na época levou um grande baque. A riqueza de detalhes e a firmeza com que conta como conseguiu uma audiência particular com o reitor retratam a importância desse fato nesta história.

Bernardete conta que escreveu um documento e foi na reitoria com o intuito de entregar em mãos para o reitor, ler o documento para ele e conversar sobre a ausência do curso de Educaçáo Artística no edital do vestibular daquele ano. Segundo ela, o secretário queria ficar com o documento para entregar depois, mas ela insistiu e conseguiu que o reitor a recebesse. Segundo ela percebeu que deveria insistir, pois ele como autoridade não iria se recusar a recebêla pessoalmente. Os momentos em que esteve no gabinete com o reitor são narrados com detalhes:

(...) ele disse: o que tu tens aí Bernardete? Eu disse: professor eu tenho um documento e eu quero ler pro senhor. Era a última chance e eu sei que fui lendo o documento devagar pra ele, eu fiquei em pé e me segurava, às vezes, eu tremia, eu me segurava e eu lendo o documento e, de repente, tocava o telefone e ele atendia e desarmava, sabe? E eu respirava... e continuava e sei que li até o final. Era sobre o vestibular, explicando o porquê das artes, uma carta suave, não muito longa, uma página e meia. Ele disse assim: tá bom Bernardete, eu entendi o que tu queres, eu advogo essa causa contigo. Se encheu de brio diante, eu acho que tinha alguma imposição, alguma influência e no dia seguinte, é incrível, porque no dia seguinte saiu um edital só pra nós.

$\mathrm{Na}$ visão da professora, esse momento foi muito importante para o futuro das artes dentro da UDESC e sua consolidação anos depois com a criação do CEART. Segundo ela, se essa questão tivesse tomado um rumo diferente, talvez a história hoje fosse outra. Nesse sentido, ela se lembra do grande desgaste sofrido durante esse período: 
Foi incrível porque era a última cartada, o máximo que eu ia levar era um não. Foi um momento de muito desgaste pra todos, pro grupo inteiro e pra mim, sobretudo, porque eu era diretora do curso, tipo assim se acontece, não porque eu era culpada, não era uma questão de orgulho próprio, mas assim, de impotência. Náo é possível que isso aconteça, que a gente deixe acontecer e, assim, podia ter mudado o curso da história.

Após essa batalha, Bernardete participou da comissão que elaborou o projeto de implantação do CEART. Segundo a professora, o curso de Educação Artística funcionava espalhado pelas sedes da UDESC na cidade, duas no centro e no campus do Itacorubi e isso era muito trabalhoso para os professores, além de dificultar a organização e integração do curso. Ela lembra que passou um verão inteiro na reitoria cuidando desse projeto juntamente com uma "boa alma" que estava ajudando datilografando o documento.

\section{A carreira docente no CEART}

A professora Bernardete deixa claro em sua entrevista que adora Adar aula e ressalta a paciência como uma de suas qualidades como professora. Sempre gostou de dar disciplinas diferentes e diz que também se divertia inventando diferentes estratégias. Salienta que, não só ministrou várias disciplinas como Percepção, Harmonia, História da Música, entre outras, como também criou disciplinas, impulsionada por conversas que tinha com os alunos sobre experiências que gostariam de ter tido no curso.

Nesse caso, cita a disciplina de Laboratório voltada para a criação, composiçãa, música de vanguarda e construção de instrumentos. Lembra também quando criou a disciplina de Música e Mídia e muitos disseram que era uma loucura porque não tinha equipamentos à disposição. Sua posição foi: "a gente cria a disciplina, o equipamento vem depois". Começou sem equipamentos mesmo e ela levava os alunos para conhecerem estúdios de gravaçăo na cidade e também chegou a levar em estúdio de TV. Segundo ela, foi o embrião do estúdio que o Departamento de Música possui hoje.

A professora lembra com alegria alguns projetos de extensão que participou e coordenou durante esses anos no CEART. Destaca os projetos que envolveram a interação entre músicos e estudantes, 
como o "Ciclo Intercâmbio Instrumental" que traz professores e músicos de fora para recitais, masterclasses, oficinas e palestras na UDESC, e o "Séries Musicais" que abre espaço para alunos e exalunos apresentarem recitais na Universidade.

Com relação à atividade de pesquisa, Bernardete diz que houve muita mudança no perfil desde o início. Segundo ela, a pesquisa no CEART se intensificou mais a partir do ano 2000 por uma necessidade de reconhecimento dos cursos, de fazer pontuação nesse quesito. Foi na década de 90 que a sua produção começou nessa direção, com um projeto de iniciação científica que levantou as escolas de música do estado de Santa Catarina, participação e publicação em encontros da Associação Brasileira de Educação Musical (ABEM) e publicações em uma revista editada pela reitoria da UDESC. Atualmente, mantém junto com outros professores do centro o grupo de pesquisa Processos Músico Instrumentais. Segundo ela, o próprio nome já dá a ideia de flexibilidade, possibilitando a entrada de professores de música com diferentes linhas de pesquisa. Ela conta que cada professor orienta alunos com trabalhos diferentes e que estão planejando realizar uma pesquisa conjunta com todo o grupo.

Bernardete é professora do Programa de Pós-Graduação em Música (PPGMUS) da UDESC, desde sua criação, na linha de práticas interpretativas. Quando o assunto é a orientação das pesquisas de mestrado ela é enfática: "orientar é uma carga pesada, uma grande responsabilidade". Nesse sentido, diz que prefere orientar no máximo dois alunos simultaneamente para garantir a qualidade do trabalho de orientação e evitar desgastes desnecessários. Explica que "gosto de orientar, mas eu fico bastante desgastada. Não consigo ser racional ao ponto de não ter envolvimento com o trabalho".

Em sua carreira docente no CEART a professora Bernardete, além dos trabalhos em ensino, pesquisa e extensão, também ocupou em várias oportunidades cargos administrativos, como chefia de departamento e direção, presidente de comissóes formadas para a elaboração de projetos envolvendo estrutura curricular e física dos cursos, entre outros. Ela lembra como foram desgastantes certos períodos em que seu envolvimento foi tamanho que não sobrava muito tempo para "estar pianista": "eu sou atualmente uma musicista professora, eu digo que eu estou pianista. Em alguns momentos eu não estava pianista, náo estive pianista, principalmente, por conta desse 
envolvimento com o administrativo. Ela diz como fez para dar conta de tudo e ainda continuar tocando: "nesse meio tempo eu sempre trabalhei no coral assim acompanhando os alunos da Ruth, com isso eu não parava de estudar, ficava ali ajudando nos ensaios e nos ensaios de naipe. Eu trabalhava o naipe dos baixos, foi muito legal”.

\title{
CEART ontem, hoje e amanhã
}

\begin{abstract}
A narrativa da professora Bernardete sobre sua história docente no ACentro de Artes da UDESC englobou a descrição de eventos e reflexóes que abarcam a concepção, a implantação e a evolução do CEART até a atualidade. Nesse sentido, é possível fazer um paralelo da sua visão sobre o passado, o presente e o que pensa sobre o futuro do centro.

Uma questão que destaca é a expansão do centro nos últimos anos. Fala sobre o crescimento do número de cursos, do aumento da produção científica, da melhoria na infraestrutura com laboratórios, equipamentos e espaço físico. Por outro lado, lembra de algumas características que foram transformadas por essa expansão que ela sente falta:
\end{abstract}

Eu acho o CEART hoje mais amplo, mais possibilidades [...]. Mas o CEART ontem era menos burocrático, muito menos burocrático. Era mais acanhado, mas tinha corpo, no sentido de que as pessoas eram mais unidas, se encontravam mais, trocavam mais dentro do próprio departamento. Eu acho que hoje nós estamos meio dispersos, eu falo pro pessoal... Talvez pelo nível de exigência, a necessidade de produção. $\mathrm{Na}$ época se dava muito mais aula, mas a gente era mais assim... uma família.

A professora considera o CEART hoje "muito simpático" e com um bom ambiente de trabalho tanto que, como ela mesma disse "acho que é tão bom que estou aqui até hoje". Segundo ela, entra para trabalhar todos os dias com prazer porque gosta do trabalho e do local. Refere-se ao CEART como sua segunda casa e como um dos lugares em que mais se sente bem:

(...) eu quero vir, eu gosto de vir. Eu poderia dizer que é a minha segunda casa. Tinha a dos meus pais, tem a casa dos meus irmãos, mas assim, é o segundo lugar onde eu venho e 
passo a maior parte do meu tempo uma grande parte do meu tempo. Me dou super bem com a minha família, adoro ir na casa dos meus irmãos, mas eu digo assim... é uma casa pra mim, me sinto bem.

Quando fala do futuro no CEART já avisa de início que a aposentadoria não está em suas perspectivas e aponta caminhos que, na sua visão, o Centro deveria seguir, sem perder de vista que a arte é o carro chefe e que "o carro chefe da arte é a mostra".

Segundo a professora, a produçâo intelectual é importante, mas a produção artística precisa ser mais valorizada e difundida no centro. $\mathrm{Na}$ sua visão, o foco do Centro de Artes precisa estar mais voltado para a produção da arte e na mostra dessa produção. Ela diz que não se trata de desvalorizar os professores que possuem uma produção intelectual maior que a produção artística, mas que seja dado um peso maior para essa produção do que vem sendo dado nos últimos anos.

Outra ação que considera importante para o futuro é investir na memória do Centro. Diz que é muito importante manter viva a memória dos professores e das pessoas que fazem a história do centro, ressaltando as açóes e pensamentos que estão por trás de cada momento histórico. Dá a dica de estudar as atas das reunióes de departamento, pois segundo ela é "uma fonte incrível de história".

Bernardete é uma professora apaixonada pelo que faz, adora dar aulas e estar com os alunos. Para ela, "o professor de piano é como uma mãe", no sentido da confiança, que tem nas mãos a orientação, que vai dar suporte para toda uma vida. É uma artista apaixonada pela arte e interessada nas sensaçóes que a arte causa nas pessoas e, nesse sentido, teve uma vida artística muito intensa tanto em sua formação quanto em sua carreira profissional. Essas características marcam sua história no CEART como alguém que foi além de um bom profissional, alguém que com seus pensamentos e açôes contribuiu na construção da realidade que temos hoje. Um centro de artes público com cinco cursos de graduação, quatro programas de pós graduação, laboratórios e auditórios em função do ensino e discussão da arte, num país em que a arte está longe das prioridades foi uma conquista e seu futuro será construído por pessoas como a professora Bernardete. 


\section{Referências}

CRESWELL, John W. Investigação qualitativa e projeto de pesquisa: escolhendo entre cinco abordagens. Trad. Sandra Mallman da Rosa. 3 - ed. Porto Alegre: Penso, 2014. 